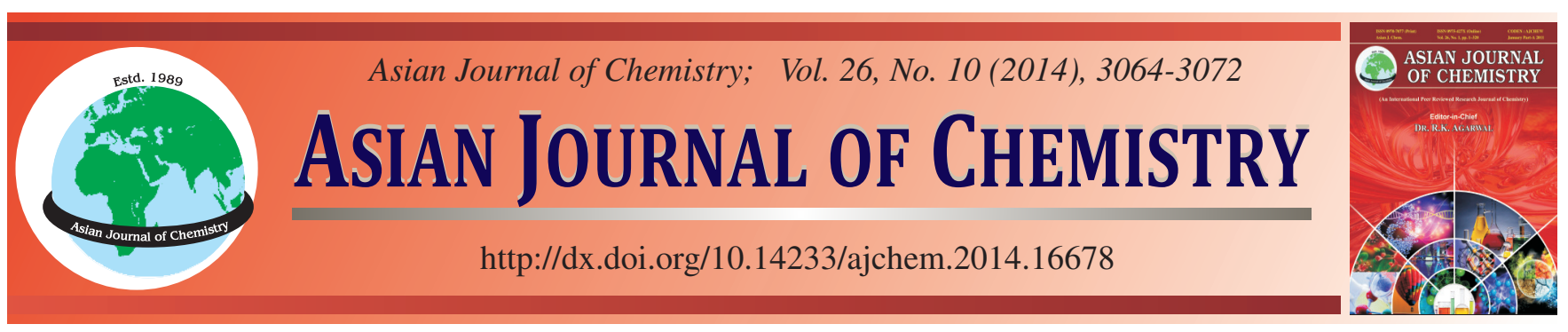

\title{
Characterization of (SBA-15)-Lipase Composite Material
}

\author{
SI-JiA Sun and QING-Zhou Zhai
}

Research Center for Nanotechnology, South Campus, Changchun University of Science and Technology, 7186 Weixing Road, Changchun 130022, Jilin Province, P.R. China

*Corresponding author: E-mail: zhaiqingzhou@163.com

Received: 12 November 2013;

Accepted: 30 Janaury 2014;

Published online: 10 May 2014;

AJC-15182

Santa Barbara Amorphous (SBA)-15 mesoporous material was synthesized by hydrothermal method using tri-block copolymer poly(ethylene glycol)-block-poly(propylene glycol)-block-poly(ethylene glycol) (Pluronic P123) as a structure-directing agent and then phenyltriethoxysilane was used to to obtain phenylated SBA-15. Then physical adsorptive method was employed to immobilize lipase to the host material. The immobilized efficiency of enzyme was improved to some extent for the phenylated SBA-15. For structural characterization of prepared samples, powder X-ray diffraction, Fourier transform infrared spectroscopy and low temperature $\mathrm{N}_{2}$ adsorptiondesorption at $77 \mathrm{~K}$ were used. The study confirmed that the enzyme went into the pore channels of the SBA-15. Scanning electron microscopic studies showed that the average particle diameter of (SBA-15)-lipase was $337 \pm 10 \mathrm{~nm}$, while the average particle diameter of (phenylated SBA-15)-lipase was $340 \pm 10 \mathrm{~nm}$. Luminescent spectra showed that the enzyme had already successfully been immobilized to the host materials and after the enzyme was immobilized into host materials the configuration had not been changed. The experimental results of activity on the hydrolysis of glycerol triacetate catalyzed by lipase indicated that compared the immobilized lipase with free lipase the catalytic activity was enhanced and the catalytic use rate of lipase was improved and the ability of resistance to temperature was improved. The repeated use number of the phenylated SBA-15 immobilized lipase as catalyst was improved compared with that of SBA15 immobilized lipase.

Keywords: SBA-15 mesoporous material, Lipase, Catalytic performance, Characterization.

ᄂ - - - - - - - - - - - - - - - - - - - - - - - - - - - - -

\section{INTRODUCTION}

Enzyme is a protein that has activity, having very vital applied value in biology, food and chemical engineering fields, etc., as biological catalyst. Enzyme catalysis has the advantages of it that the selectivity is high, the catalytic efficiency is high, the reactive condition is mild and no environmental pollution exists, etc, while most of free enzymes have the disadvantages of it that the enzymes are easily dissolved in water, the stability is poor, enzyme purification is difficult after reaction and the recovery is difficult and repetition cycle use is not easy, etc. These disadvantages made free enzymes' application be limited. The above shortcomings in the use of free enzymes are overcome after enzymes are immobilized on the supports via physical, chemical method ${ }^{1}$. The toxicity of inorganic support material is small and surface property is controllable and the support is easily recovered and regenerated. Ordered silica based mesoporous material has the advantages that specific surface area is big and pore size distribution is narrow and chemical stability is good and surface is easily modified, etc., being suitable to biological macromolecule's separation, purification and enzyme's immobilization and having become the development and applied foreground of good carrier. The immobilization of protein in ordered pore material has caused scientists' great concern ${ }^{1,2}$. In mesoporous material, MCM (Mobil Composition of Matter)-n was first synthesized in $1992^{3,4}$. Its appearance is ground-breaking milestone in the synthesis of mesoporous material. However, there are some shortcomings of its own, for example, its pore size is smaller and the hydrothermal stability is not high etc, which makes its application subjected to certain limitations. Compared with MCM-n, SBA (Santa Barbara Amorphous)-15 has larger specific surface area, larger pore size, higher hydrothermal stability and its thermal stability is higher and its surface contains abundant silanol and is easily modified ${ }^{5,6}$. Therefore, SBA-15 has better potential applied value. This kind of mesoporous material is non-toxic to biology $\mathrm{y}^{7-9}$. Balkus et al. first explored nanoporous silica based mesoporous material for enzyme immobilization ${ }^{10}$. Pore size, pore structure, surface characteristic, morphological structure, functionalized group modification (-SH, - $\mathrm{Cl},-\mathrm{NH}_{2},-\mathrm{COOH},-\mathrm{CH}=\mathrm{CH}_{2},-\mathrm{CH}_{3},-\mathrm{C}_{2} \mathrm{H}_{5}$, etc)and metal ion modification ( $\mathrm{Al}, \mathrm{Co}$, etc) of mesoporous material, size dimension, isoelectric point and concentration of enzyme molecule, $\mathrm{pH}$ value of immobilization solution 
factors, etc, affect the enzyme immobilization in mesoporous materials. Yiu et al. ${ }^{11}$ studied the immobilization of insulin in MCM-41 and established optimum immobilization conditions. Ji et al. ${ }^{12}$ reported the adsorptive study of bovine serum albumin in Al-MCM-41,focusing on observing the effect of acidity, silicon/aluminum ratio, etc, on adsorption.

Lipase (triacylglycerol ester hydrolase, E.C.3.1.1.3) ${ }^{13}$ is a single-chain protein. Its molecular weight is $38 \mathrm{kDa}$ with a molecular size of $6.3 \times 5.6 \times 4.2 \mathrm{~nm}$. It can not only catalyze glyceride to generate fatty acids, but also can be used in the esterification reaction. In the dairy industry, lipase can catalyze the hydrolysis of the dairy ester in the dairy product to generate fatty acid to let milchigs have sweet sour. Lipase has already extensively been applied to food, chemical engineering and pharmaceutical industry. However, the coefficient of direct utilization of lipase is not high and there are a lot of problems to limit applications. First of all, the reuse ratio of enzyme is not high, causing enzyme's disposable use and increasing the cost. Meanwhile, requirements of lipase to environment are high that it is more sensitive to the changes in temperature, acid-base degree, $\mathrm{pH}$ value and it is easy to denature and inactivate. In order to enhance its activity and stability to overcome the above-stated drawbacks, via immobilization method important biological catalyst lipase is encapsulated in a special phase to improve its activity and stability. In this paper SBA15 and phenylated (SBA-15) mesoporous material were prepared and by means of physical adsorption method lipase is immobilized in the two host materials. This paper reports the preparation conditions and structural characterization of (SBA-15)-lipase and [phenylated (SBA-15)]-lipase composite materials and studied the results on their catalytic hydrolysis of triavetin.

\section{EXPERIMENTAL}

Lipase (prepared from porcine pancreas, biological grade, E.C.3.1.1.3) was purchased from Sinopharm Chemical Reagent Co., Ltd., China, and used without further purification. The reagents for the preparation of SBA-15 include pluronic P123 triblock copolymer, poly(ethylene glycol)-block-poly (propylene)-poly (ethylene glycol) was purchased from SigmaAldrich, USA. TEOS (tetraethylor-thoxysilicate) and hydrochloric acid were obtained from Beijing Chemical Plant, China. The reagents for the preparation of phenylated SBA15 are phenyltriethoxysilane which was purchased from Fine Chemical Plant, Zhejiang Huagong Technology Group Limited Company, China. Benzene and absolute ethanol was the product of Sinopharm Chemical Reagent Co., Ltd., China. The reagents for the analysis of lipase content are dibromo- $p$ chloro-chlorophosphonazo (DBC-CPA), a gift from Changke Research Institute of Reagent, Jinsheng Chemical Co., Ltd., China. Sulfuric acid was purchase from Beijing Chemical Plant, China. Catalytic experimental reagents for lipase: Sodium dihydrogen phosphate, disodium hydrogen phosphate and triavetin came from Liaobei Chemical Plant, The Second Chemical Reagent Plant of Kaiyuan City, Xiya Reagent, China, respectively. Deionized water was used throughout all the experiments. Unless otherwise specified, all reagents were of analytical grade.
Synthesis of SBA-15: SBA-15 synthesis method is as follows: $2 \mathrm{~g}$ of tri-block copolymer poly(ethylene glycol)block-poly(propylene glycol)-block -poly(ethylene glycol) was dissolved in $15 \mathrm{~g}$ of water and $60 \mathrm{~g}$ of $2 \mathrm{~mol} / \mathrm{L}$ hydrochloric acid solution, stirred up to complete dissolution. At $40{ }^{\circ} \mathrm{C} 4.25$ $\mathrm{g}$ of TEOS was added and stirred for $24 \mathrm{~h}$ and then transferred into an autoclave. At $100{ }^{\circ} \mathrm{C}$, crystallization was made for 48 $\mathrm{h}$ at constant temperature. After the crystallization was finished,filtration was made and the product was washed using deionized water. The product was dried at room temperature. The above product was placed in a ceramic crucible and put into a muffle oven and calcined at $550{ }^{\circ} \mathrm{C}$ for $24 \mathrm{~h}$ to eliminate the tri-block copolymer template. A SBA-15 mesoporous material powder was obtained ${ }^{14}$.

Preparation of phenylated SBA-15: $1 \mathrm{~g}$ of the calcined SBA-15 was placed in the mixed solution which was made up of $10 \mathrm{~mL}$ of benzene and $10 \mathrm{~mL}$ of phenyltriethoxysilane. This mixture was continuously stirred at room temperature for $70 \mathrm{~h}$. The product was then filtrated and washed twice using absolute ethanol. Finally, the product was dried in air at room temperature and calcined in static air at $300{ }^{\circ} \mathrm{C}$ for $6 \mathrm{~h}$ to obtain the phenylated SBA-15 product, designed as $\mathrm{Ph}-$ (SBA-15) with a content of phenyl of $6.7 \%(\mathrm{w} / \mathrm{w})^{15}$.

Immobilization of lipase: To a $25 \mathrm{~mL}$ beaker, in turn was added $0.25 \mathrm{~g}$ of calcined SBA-15/Ph-(SBA-15), $5 \mathrm{~mL}$ of $5 \mathrm{mg} / \mathrm{mL}$ lipase solution. $5 \mathrm{~mL}$ of $\mathrm{pH}=6.4 \mathrm{NaH}_{2} \mathrm{PO}_{4}-\mathrm{Na}_{2} \mathrm{HPO}_{4}$ buffer solution. The mixture was shaken for adsorption for 24 $\mathrm{h}$ at $4{ }^{\circ} \mathrm{C}$. The mixed solution was centrifugated at a speed of $6000 \mathrm{rpm}$. The solid composite material was washed with distilled water and the supernatant clear solution was retained. The operation was repeated until lipase could not be detected in the supernatant clear solution. The supernatant clear solution and solid composite material were obtained and the supernatant clear solutions were merged. The composite material was dried at room temperature and an objective product was obtained. It is designed as (SBA-15)-lipase/[Ph-(SBA-15)]-lipase.

Determination method for lipase: Using dibromo- $p$ chloro-chlorophosphonazo spectrophotometric method, the protein content in the supernatant clear solution was determined via subtraction method. The content of the protein adsorbed was calculated by the mass balance before and after adsorption

In turn, $1.2 \mathrm{~mL}$ of $1.0 \times 10^{-3} \mathrm{~mol} / \mathrm{L} \mathrm{DBC}$-CPA chromogenic agent and $1 \mathrm{~mL}$ of $1 \mathrm{~mol} / \mathrm{L} \mathrm{H}_{2} \mathrm{SO}_{4}$ solution were added to the two $10 \mathrm{~mL}$ volumetric flasks. To one of the volumetric flasks, 2-7 mg of the protein standard solution was added and diluted with water to the mark and shaken. The solution was allowed to stand for $35 \mathrm{~min}$ at room temperature and using the corresponding reagent blank as a reference and with $1 \mathrm{~cm}$ cell absorbance was measured at $600 \mathrm{~nm}^{16}$.

Determination method for catalytic activity of lipase: In a $250 \mathrm{~mL}$ beaker, $2 \mathrm{~g}$ of glycerol triacetate, $25 \mathrm{~mL}$ of the buffer solution of $\mathrm{pH}=6.4 \mathrm{Na}_{2} \mathrm{HPO}_{4}-\mathrm{NaH}_{2} \mathrm{PO}_{4}$ and $50 \mathrm{~g}$ of deionized water were added, which was continuously stirred with uniform speed for $0.5 \mathrm{~h}$ at $35^{\circ} \mathrm{C}$. When in the beaker flocculus material appeared, the stirring speed was gradually accelerated until the $\mathrm{pH}$ was remained unchanged. Adding a certain mass of lipase, a $0.05 \mathrm{~mol} / \mathrm{L} \mathrm{NaOH}$ was used to titrate 
the fatty acid produced by the hydrolysis of glycerol triacetate catalyzed by the lipase, and the volume of consumed $\mathrm{NaOH}$ was recorded. Compared with the blank experiment, the activity of the lipase can be known. The procedure for the determination of (SBA-15)-lipase activity was in agreement with that for the determination of lipase ${ }^{13}$.

Characterization techniques: A 722S spectrophotometer (Shanghai Lingguang Technology Co., Ltd., China) was used for absorbance measurement, equipped with $1 \mathrm{~cm}$ cell. X-ray diffraction (XRD) was employed to identify the phases of the materials. The experiments were performed on a D8/ADVANCE (Bruker, Germany) powder X-ray diffractometer equipped with a CuK $\alpha$ radiation source (Wavelength, $1.5406 \AA$ ) run at $25 \mathrm{kV}$, $20 \mathrm{~mA}$. Small-angle XRD patterns were obtained from $0.6^{\circ}$ to $10^{\circ}$ of $2 \theta$, with a step size of $0.02^{\circ}$ and the time step of $1 \mathrm{~s}$. The determination angle $2 \theta$ value of wide-angle XRD ranged from $10^{\circ}$ to $80^{\circ}$ with the measured step length of $0.05^{\circ}$ and the time step of $1 \mathrm{~s}$. The $77 \mathrm{~K}$ low temperature $\mathrm{N}_{2}$ adsorptiondesorption experiments were carried out on an ASAP 2020 (Micromeritics Instrument Corporation, America) surface area and porosity analyzer. The sample was vacuumized at room temperature for $2 \mathrm{~h}$. The sample was not heated during degassing to prevented protein denaturation. Specific surface area was measured by BET (Brunauer-Emmett-Teller) method ${ }^{17}$ and BJH (Barrett-Joyner-Halenda) method ${ }^{18}$ was used for the analysis of pore structure of the sample. The morphology was analyzed with a XL 30 ESEM FEG (American FEI Company) scanning electron microscope. The accelerating voltage used was $20 \mathrm{kV}$. Fourier transform infrared (FT-IR) measurements were completed using a Vertex-70 (Bruker Company, Germany) spectrometer with a resolution of $4 \mathrm{~cm}^{-1}$ and 32 scans, using $\mathrm{KBr}$ pressing slice technique. The scan wavelength range ranged from 4000 to $400 \mathrm{~cm}^{-1}$. The luminescence experiments were carried out on a Japanese Hitachi U-4100 apparatus and the work environment was $25^{\circ} \mathrm{C}$.

\section{RESULTS AND DISCUSSION}

Lipase determination working curve and immobilization amount calculation: The content of lipase was determined by using dibromo- $p$-chloro-chlorophosphonazo spectrophotometry ${ }^{16}$. According to Beer's law,working curve for the determination of lipase was obtained. The linear range of method was 1-700 $\mu \mathrm{g} / \mathrm{mL}$, apparent molar absorptivity was $2.79 \times 10^{4} \mathrm{~L} \mathrm{~mol}^{-1} \mathrm{~cm}^{-1}$, and its linear regression equation of method was:

$$
\mathrm{A}=0.0006 \mathrm{C}+0.0033
$$

where $\mathrm{A}$ is absorbance; $\mathrm{C}$ is concentration of lipase in $\mu \mathrm{g} / \mathrm{mL}$.

$$
\mathrm{C}=(\mathrm{A}-0.0033) / 0.0006
$$

A $350 \mu \mathrm{g} / \mathrm{mL}$ of lipase were parallel determined five times by this method, relative standard error of the method calculated was $1.31 \%$.

The lipase amount adsorbed in the mesoporous material is equals to the total amount of lipase minus the lipase amount in supernatant, which can be calculated by the following formula:

$$
\mathrm{Q}_{\mathrm{t}}=\left(\mathrm{C}_{\mathrm{i}}-\mathrm{C}_{\mathrm{t}}\right) \times \mathrm{V} / \mathrm{W}
$$

where $Q_{t}$ is the amount of immobilized lipase on carrier at the time of $\mathrm{t}\left(\mathrm{mg} / \mathrm{g}\right.$, mg lipase per gram support); $\mathrm{C}_{\mathrm{i}}$ and $\mathrm{C}_{\mathrm{t}}$ are the concentration of lipase in the solution at initial time and at the time of $\mathrm{t}(\mathrm{mg} / \mathrm{mL})$, respectively; $\mathrm{V}$ is the volume of the reaction medium $(\mathrm{mL}) ; \mathrm{W}$ is the weight of the carrier $(\mathrm{g})$.

Optimum condition for lipase immobilization: In Fig. 1, curve (a) is the influence curve of $\mathrm{pH}$ impact on SBA15 immobilization lipase, while curve (b) showed the of $\mathrm{pH}$ impact on Ph-(SBA-15) immobilization lipase. It can be seen from the curve (a) that when the $\mathrm{pH}$ value of buffer solution was in range 5.8-6.4, the adsorption amount gradually increased with the increase of $\mathrm{pH}$ value. When the $\mathrm{pH}$ value was between 6.4 and 7, the adsorption quantity declined gradually with the increase of $\mathrm{pH}$ value. When the $\mathrm{pH}$ value of buffer solution was 6.4, the maximum adsorption appeared. This is consistent with the isoelectric point of lipase and at this time the electrostatic repulsive force existed between the lipase and SBA 15 surface was the smallest. The isoelectric point of general silica material is within the scope of 0.5 to $3.7^{19-21}$, while the isoelectric point of the SBA 15 is in the range of 2.7 to $3.7^{21,22}$. The isoelectric point is the $\mathrm{pH}$ value in solution at which the sum of charges on the protein is zero. At a pH below than pI, a protein is positively charged, whereas it is negatively charged at a $\mathrm{pH}$ above the $\mathrm{pI}^{21}$. When the $\mathrm{pH}$ value was lower than the isoelectric point, the electrostatic repulsive force increased between mesoporous SBA-15 and lipase that carried the identical positive electric charge, which made the adsorption quantity descend. When the $\mathrm{pH}$ value was higher than the isoelectric point, the electrostatic repulsive force increased between SBA-15 and lipase that carried the identical negative electric charge, which made the adsorption quantity decline. The whole process of adsorption was finished through the electrostatic force of the mesoporous SBA 15 and lipase, hydrogen bonding and hydrophobic effect. Fig. 2 is the effect of adsorption time on the immobilization of lipase for SBA15 and $\mathrm{Ph}-(\mathrm{SBA}-15)$ at different $\mathrm{pH}$ value. From the figure it can be observed that the adsorption amount of lipase by $\mathrm{Ph}$ (SBA-15) reduced with respect to that of SBA-15 and the adsorption time shorten and the speed of reaching adsorption equilibrium was faster. This resulted from the surface modification of the SBA-15. Phenyl was used to replace the surface's torpid silanols, which made the pore channels size of SBA-15 reduce and the surface activity be strengthened. The results of lipase concentration effect on the adsorption on SBA-15 and $\mathrm{Ph}-(\mathrm{SBA}-15)$ showed that when the lipase concentration increased from 0 to $5 \mathrm{mg} / \mathrm{mL}$, the adsorption amount of lipase gradually increase with rise of its concentration. At $5 \mathrm{mg} / \mathrm{mL}$, the adsorption amount was the largest. Afterwards, lipase adsorption amount decreased slightly. To sum up, the following results are obtained. The optimum conditions for SBA-15 immobilization lipase are: adsorption time $36 \mathrm{~h}$, solution concentration $5 \mathrm{mg} / \mathrm{mL}, \mathrm{pH}$ value 6.4 . The immobilization amount is $74.67 \mathrm{mg}$ (lipase)/g (SBA-15). The optimum conditions for Ph-(SBA-15) immobilization lipase are: adsorption time $24 \mathrm{~h}$, solution concentration $5 \mathrm{mg} / \mathrm{mL}$, $\mathrm{pH}$ value 6.4. The immobilization amount is $61.56 \mathrm{mg}$ (lipase)/g Ph-(SBA-15).

Phase analysis: The XRD diffraction patterns of lipase, SBA-15, (SBA-15)-lipase, Ph-(SBA-15) and [Ph-(SBA-15)]lipase samples are presented in Fig. 3. Curve (a) is the diffraction pattern of lipase, from which it can be seen that no characteristic peaks appeared. This is due to that the lipase 


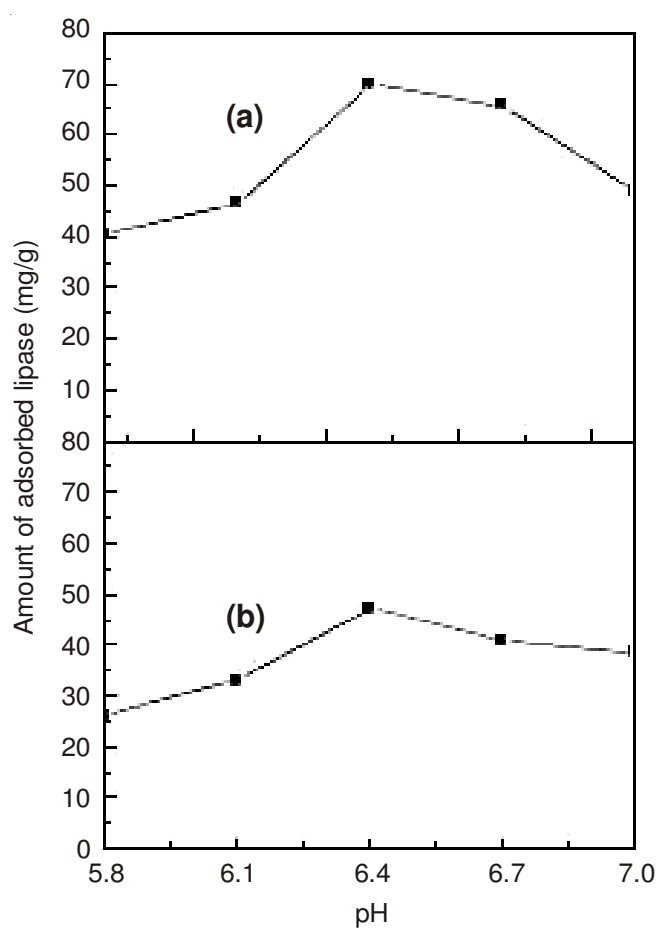

Fig. 1. Effect of different $\mathrm{pH}$ value on the adsorption of lipase on SBA 15 (a) and Ph-(SBA-15) (b). Experimental conditions: initial concentration of lipase $=5 \mathrm{mg} / \mathrm{mL}$, adsorption time $=24 \mathrm{~h}$, adsorbent dosage $=25 \mathrm{mg} / \mathrm{mL}$

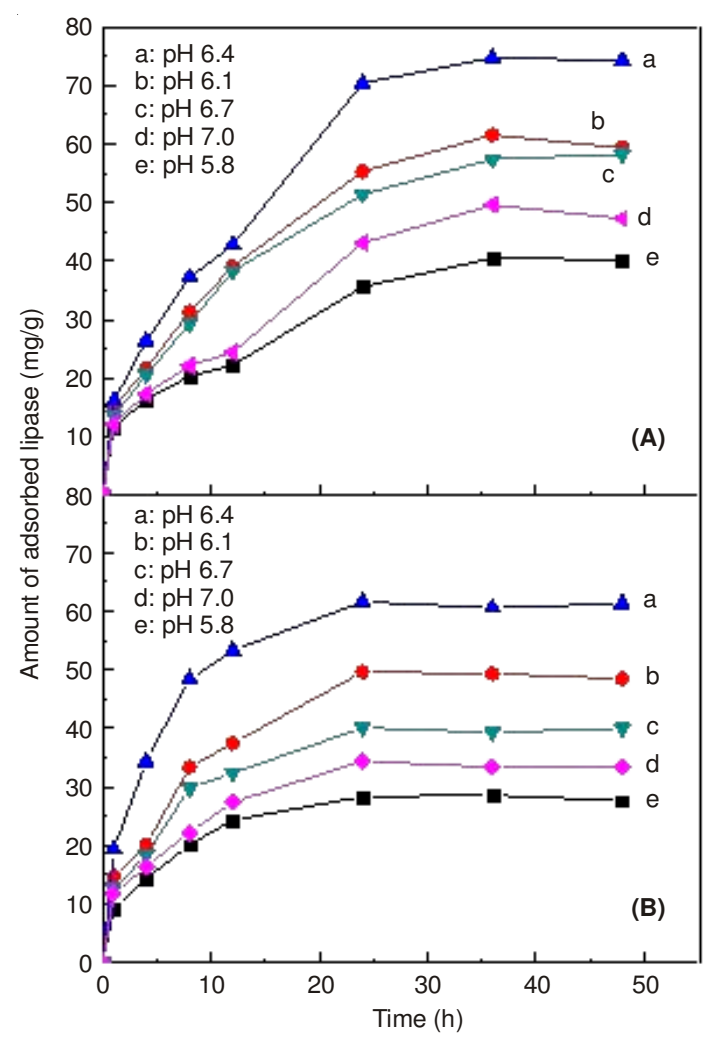

Fig. 2. Effect of adsorption time on the adsorption of lipase on SBA-15 (A) and Ph-(SBA-15) (B). Experimental conditions: initial concentration of lipase $=5 \mathrm{mg} / \mathrm{mL}$, adsorbent dosage $=25 \mathrm{mg} / \mathrm{mL}$

itself is an amorphous phase and no characteristic peaks exist. However, for the XRD curve (b) of SBA-15 sample there is a strong diffraction peak (100) appeared in low angle diffraction district and the two weaker intensity diffraction peaks (110,
200) emerged, which showed that the quality of SBA-15 was good and the skeleton structure was highly ordered ${ }^{14}$. From curve (c) it can be seen that for the (SBA-15)-lipase sample the characteristic peaks of (100), (110), (200) were still retained. This showed that after lipase emerge into the SBA- 15 by physical adsorption, the framework structure of the SBA-15 still existed and maintained a highly orderly and its framework structure was not changed. The entry of lipase did not affect the framework integrity of the SBA-15 material. Compared curve (d) with curve (b), the characteristic peak of the SBA-15 was still present. This showed that the phenylated modified SBA15 skeleton structure was intact and highly ordered. And further compared curve (e) with curve (d) it can be known that for [phenylated (SBA-15)]-lipase sample the characteristic peaks of the phenylated (SBA-15) were still retained, which showed that after the physical adsorption of lipase into phenylated (SBA-15) the framework structure of phenylated (SBA-15) was not changed and the framework integrity of the material was not affected and retained highly ordered. However, the (100) diffraction intensity decreased slightly after lipase uptake, showing larger contrast in density between the silica wall and the open pores than between the silica walls and the lipase molecules. Fig. 4 is the wide-angle XRD diffraction patterns of lipase, SBA-15, (SBA-15)-lipase, phenylated (SBA$15)$ and [phenylated (SBA-15)]-lipase samples. For the (SBA15)-lipase sample, no new peak appeared with respect to SBA15. The [phenylated (SBA-15)]-lipase also still retained the characteristic peaks of phenylated SBA-15 and no new phase was formed.

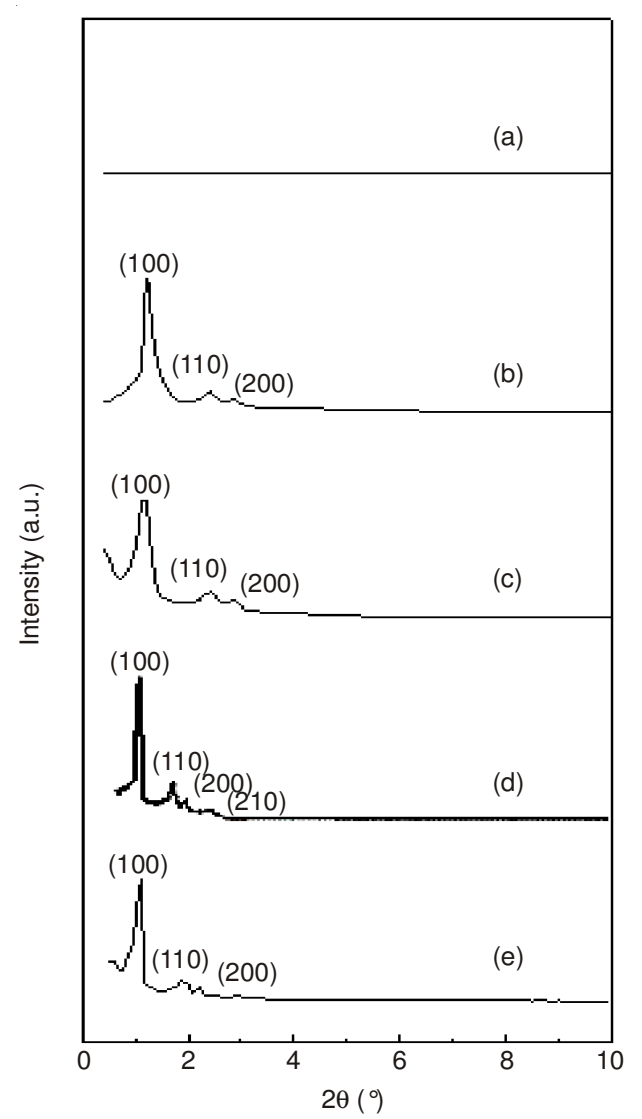

Fig. 3. Small angle XRD pattern of sample: (a) lipase, (b) SBA-15, (c) (SBA15)-lipase, (d) Phenylated (SBA-15), (e) [Phenylated (SBA-15)]-lipase 


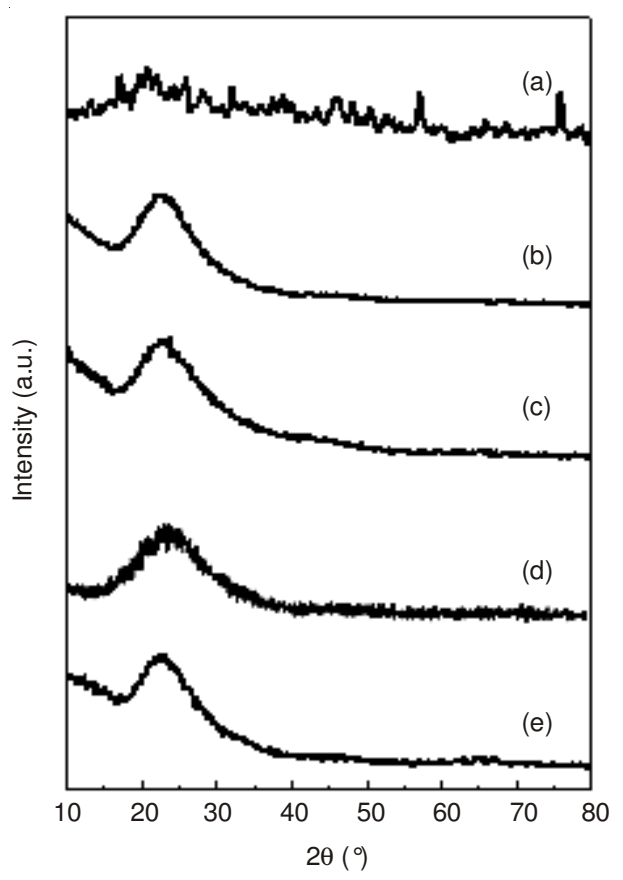

Fig. 4. Wide angle XRD pattern of sample: (a) lipase, (b) SBA-15, (c) (SBA15)-lipase, (d) Phenylated (SBA-15), (e) [Phenylated (SBA-15)]-lipase

Porosity and surface area: Fig. 5 shows nitrogen adsorption-desorption isotherms of SBA-15 and (SBA-15)-lipase. Table-1 gives the pore structure parameters before and after immobilization protein. It can be seen that as soon as adsorption of lipase occurred, the pore volume decreased, suggesting that lipase occupied the space of host channels. Both isotherms of sample SBA-15 and (SBA-15)-lipase belong to IV type (Brunauer definition) in the IUPAC classification and both samples show H1-type hysteresis loop, indicating that the pore channels are cylindrical pore shape $\mathrm{e}^{23}$. The characteristics hysteresis loops of nitrogen adsorption-desorption isotherm of the prepared samples have one obvious adsorption and desorption branch. The steep adsorption branch and desorption branch can show that the prepared SBA-15 and (SBA-15)lipase composite materials have relatively narrower mesoporous size distribution. The three stages of curve adsorption are consistent with mesoporous material adsorption characteristics. In the adsorption-desorption isotherms, molecule was adsorbed on the surface of molecular sieve in the form of a single molecule, and the multi-molecular layer adsorption did not occur until the pressure was high enough. Over the range of a relative partial pressure $\left(p / p_{0}\right)$ of $0-0.685$ for SBA-15 and over the range of a relative partial pressure of 0-0.657 for (SBA15)-lipase, as the relative pressure increased, molecules adsorbed on the outside surface in single layer to multilayer and the volume adsorbed increased. As capillary condensation began to take place on ring adsorption membrane surface on pore wall and desorption began from pore mouth ball bend moon shape surface, thus for adsorption-desorption isotherm often a hysteresis loop exists. The relative partial pressure range after immobilization protein is smaller than that before the immobilization. This is due to it when lipase was immobilized in SBA-15, the SBA-15 pore channels were occupied to result in SBA-15 pore volume decrease. When the relative partial pressure of SBA-15 reached 0.685 and the relative partial pressure of (SBA-15)-lipase reached 0.657, due to the capillary condensation phenomenon occurrence, the adsorption branches and desorption branches of the adsorption-desorption isotherms appeared to a sudden change. The jump point of $\mathrm{N}_{2}$ adsorptiondesorption isotherm of the immobilized protein SBA-15 advances than that before the immobilization. In the material having mesoporous channels, the relative pressure of capillary enrichment (capillary agglomeration) phenomenon occurred is an increasing function of the mesoporous pore diameter. Namely, the greater the mesoporous channel diameter of a material is, the higher the relative pressure of capillary agglomeration phenomenon occurred is, which can be proved by the aperture parameters of various materials. The decrease of amount of adsorbed $\mathrm{N}_{2}$ for (SBA-15)-lipase can be attributed to the decrease of pore volume and smaller pore sizes resulted in capillary enrichment occurrence at a lower relative pressure. In addition, that the hysteresis appeared in the higher relative pressure range is in accordance with the mesoporous characteristics of SBA-15, which proved that after lipase was immobilized in SBA-15, characteristics of the mesoporous structure still existed. It can also be seen from the nitrogen adsorptiondesorption curves of prepared materials that: For the prepared SBA-15, when the relative partial pressure reached 0.871 , the adsorption branch overlapped with desorption branch again, which is the phenomenon that desorption branch lagged the adsorption branch no longer. For the prepared (SBA-15)-lipase composite sample, the phenomenon that desorption branch lags the adsorption branch did not appear. When the relative pressure of sample reached 0.814 , the phenomenon that desorption branch lags the adsorption branch did not appear again. This phenomenon is mainly when the mesoporous channels have been filled with gas under the higher relative pressure and after capillary enrichment phenomenon accomplished, the adsorption behavior mainly occurred in the outer surface of the material and this process is reversible, leading the phenomenon that desorption branch lags the adsorption branch did not appear again. The related data of various parameters were based on the adsorption branch of the nitrogen adsorption-desorption isotherms. It is found by comparing properties of the two samples before and after the immobilization protein that the average pore diameter and the pore volume decreased respectively from $8.14 \mathrm{~nm}$ and $1.06 \mathrm{~cm}^{3} / \mathrm{g}$ for SBA-15 to $8.01 \mathrm{~nm}$ and $0.85 \mathrm{~cm}^{3} / \mathrm{g}$ for the (SBA-15) -lipase and the BET

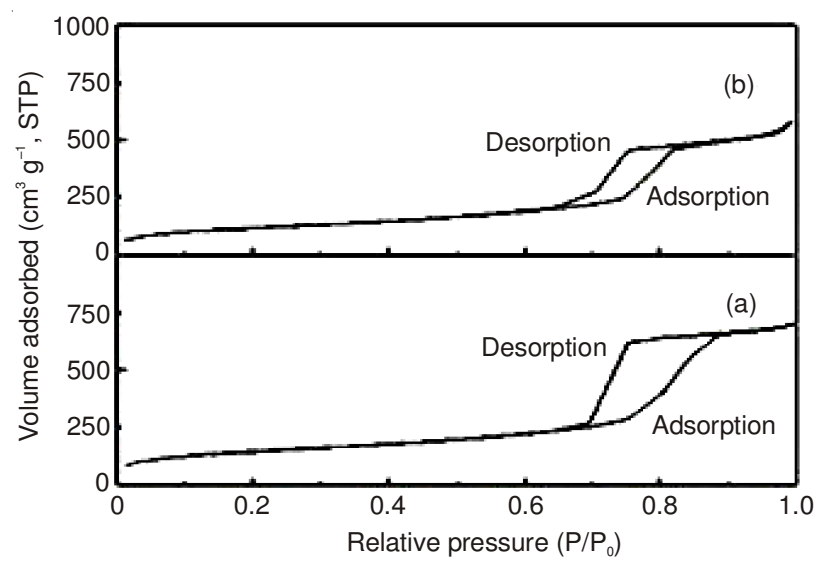

Fig. 5. Low temperature nitrogen adsorption-desorption isotherm of sample: (a) SBA-15; (b) (SBA-15)-lipase 
SBA-15 was $330 \pm 10 \mathrm{~nm}$, while the sample (SBA-15)-lipase has an average particle diameter of $337 \pm 10 \mathrm{~nm}$. Average diameter of the immobilized composite materials increased, which is mainly because the lipase introduction led to the increase of the micro particle volume. However, compared the immobilized composite material with SBA-15, the degree of order decreased. Fig. 8 shows the scanning electron microscopic analysis patterns of phenylated SBA-15 and (phenylated SBA-15) lipase samples. The two materials presented ordered fibrous structure. The average particle diameter of the sample phenylated SBA-15 was $335 \pm 10 \mathrm{~nm}$, while the sample (phenylated SBA15)-lipase has an average particle diameter of $340 \pm 10 \mathrm{~nm}$. Average diameter of the immobilized composite material particles increased. This is mainly because the lipase introduction resulted in the increase of the micro particle volume. However, compared the immobilized composite material particles with SBA-15, the degree of order declined.

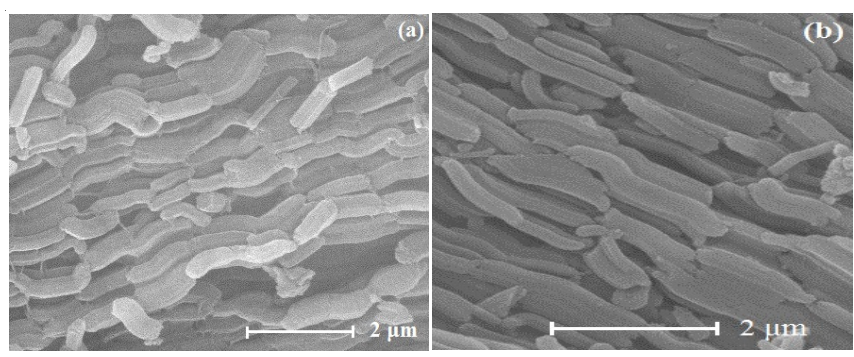

Fig. 7. Scanning electron micrographs of samples: (a): SBA-15; (b): (SBA-15)-lipase

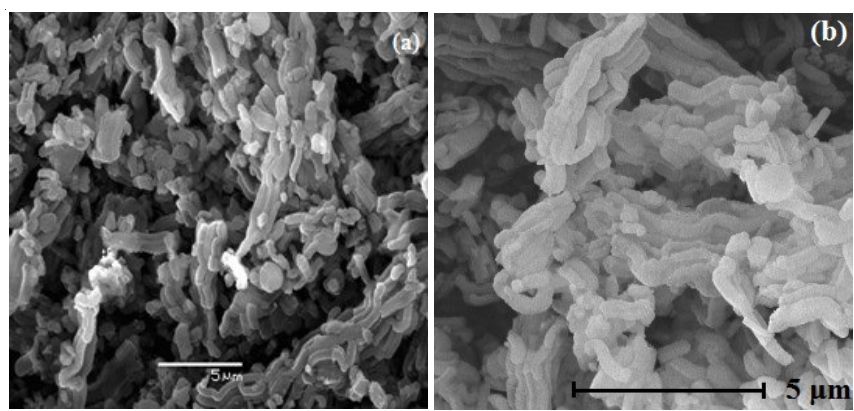

Fig. 8. Scanning electron micrographs of samples: (a): (phenylated SBA15)-lipase; (b): (SBA-15)-lipase

IR spectra: Fig. 9 shows the FT-IR spectra of lipase, SBA15, (SBA-15)-lipase samples from 4000 to $400 \mathrm{~cm}^{-1}$, respectively. For SBA-15, $3436 \mathrm{~cm}^{-1}$ is assigned to a non-symmetric stretching vibration mode resulting from the $\mathrm{Si}-\mathrm{OH}$ groups observed from the surface of SBA-15. This vibration is also assigned to the vibrational modes of $\mathrm{Si}-\mathrm{OH}$ unreacted hydroxyl groups on the SBA-15 silica surface or may be assigned to isolated and geminal hydroxyl groups, respectively. $1632 \mathrm{~cm}^{-1}$ is the flexural vibration of $\mathrm{H}-\mathrm{O}-\mathrm{H}$ groups adsorbed onto the surface and channels of SBA-15 silica material. 1084 and 802 $\mathrm{cm}^{-1}$ arose from the non-symmetric and symmetric stretching vibration of $\mathrm{Si}-\mathrm{O}-\mathrm{Si}$ groups of $\mathrm{SiO}_{4}$ tetrahedron, respectively. $967 \mathrm{~cm}^{-1}$ resulted from the stretching vibration of Si-OH groups. $464 \mathrm{~cm}^{-1}$ is T-O bending vibration. After SBA-15 immobilized lipase (curve c), the characteristic peaks of SBA-15 emerged for the (SBA-15)-lipase, showing that integrity of the framework of SBA-15 in the composite material was retained. The characteristic peaks at 1389 and $953 \mathrm{~cm}^{-1}$ of lipase appeared in the (SBA-15)-lipase composite material, indicating that lipase has already entered into SBA-15 host material. For phenylated SBA-15 sample, in the infrared spectrum the bands at 1431, 740, $698 \mathrm{~cm}^{-1}$ appeared (curve d), which are due to $\mathrm{C}-\mathrm{H}$ deformation vibration peaks of benzene aromatic ring. $740 \mathrm{~cm}^{-1}$ may also be assigned to a stretching vibration peak of $\mathrm{C}=\mathrm{C}$ in benzene aromatic ring. The successful phenylation of SBA-15 was shown. Comparing the infrared spectra before and after lipase immobilization in phenylated SBA-15 sample (curve d,e) it can be seen that the composite material retained the characteristic infrared peaks of host material, which indicated integrity of the framework of SBA-15 host.

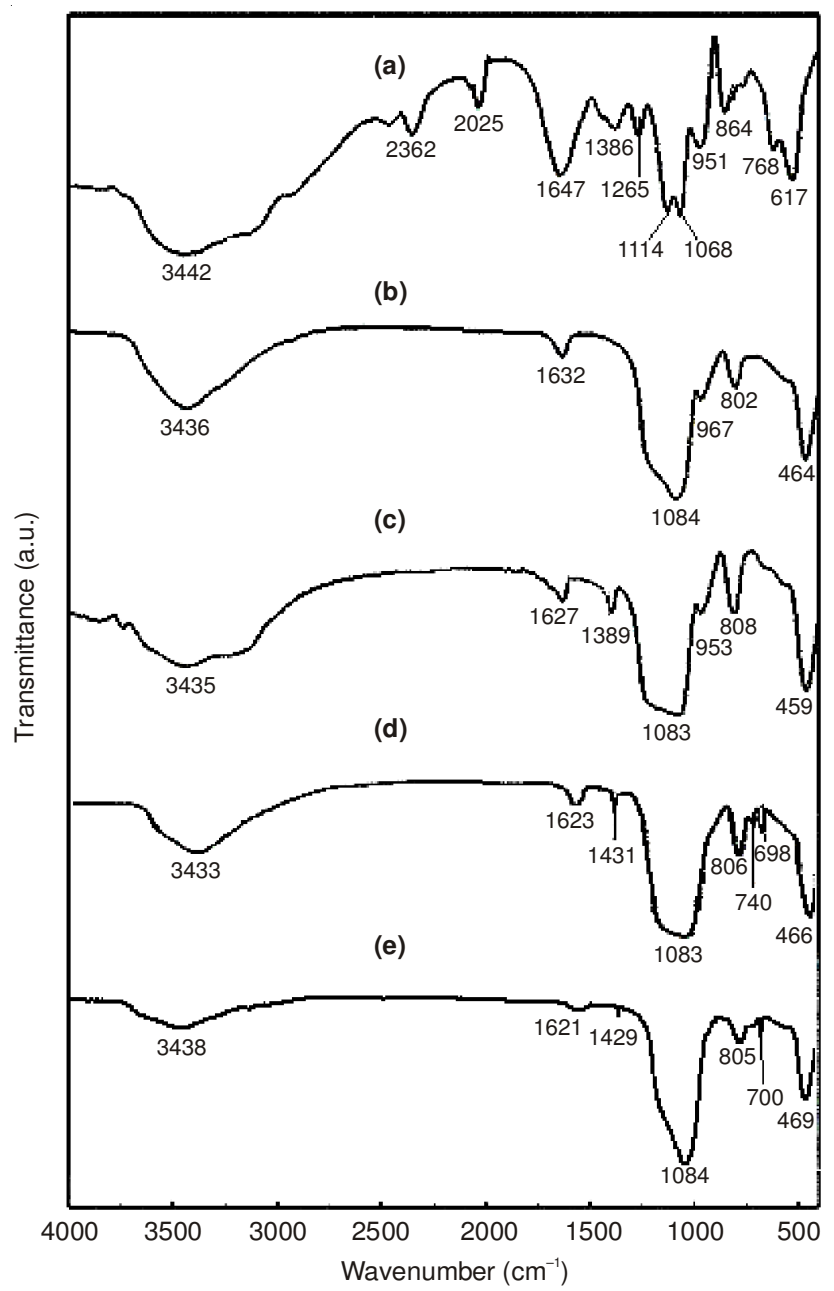

Fig. 9. Infrared spectra of samples: (a) lipase; (b) SBA-15; (c) (SBA-15)lipase; (d) phenylated SBA-15; (e) (phenylated SBA-15)-lipase

Luminescence spectra: In Fig. 10, patterns (A), (B) and (C) are luminescence spectra of lipase, (SBA-15)-lipase and (phenylated SBA-15)-lipase. In it, (a) is excitation spectrum and (b) is emission spectrum. From the figure it can be seen that peak position of the emission spectra of lipase, (SBA-15)-lipase and (phenylated SBA-15)-lipase appeared at 340, 341 and 340 $\mathrm{nm}$, respectively and the peak positions are basically consistent. It indicates that luminescence is assigned to the lipase. Lipase was respectively immobilized inside the SBA-15 and phenylated SBA-15, no making its conformation cause change or denaturation. The lipase maintained good structure. 


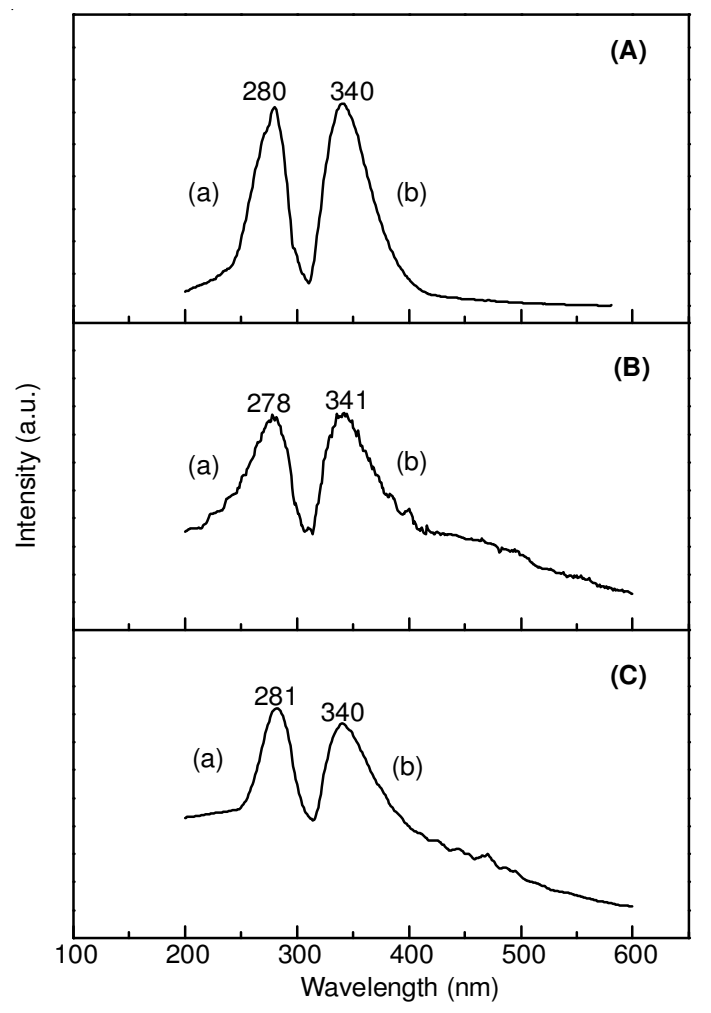

Fig. 10. Luminescence spectra of samples: (A) Lipase; (B) (SBA-15)-lipase; (C) (phenylated SBA-15)-lipase; in it (a) Excitation spectrum; (b) Emission spectrum

Catalytic activity: Fig. 11 showed the effect of buffer solution $\mathrm{pH}$ on the catalytic hydrolysis of glyceryl triacetate by lipase and (SBA-15)-lipase. From the figure we can see that for lipase at buffer solution $\mathrm{pH}=6.4$ the maximum activity appeared and the catalytic activity was $61.3 \mathrm{U} / \mathrm{g}$, while for (SBA-15)-lipase the maximum value appeared at the buffer $\mathrm{pH}=7.4$ and its catalytic activity was $71.3 \mathrm{U} / \mathrm{g}$. It shows that the catalytic activity of (SBA-15)-lipase appeared in the higher $\mathrm{pH}$ relative to the one of lipase, which is mainly because the carrier made proton tend to optimum $\mathrm{pH}$ value direction. At the same time, because of the shielding effect of mesoporous SBA-15 structure, SBA-15 surface hydroxyl and lipase surface hydrophobic layer combine to make the internal active point of lipase get the full contact with glyceryl triacetate substrate, which could improve the activity of the enzyme and adaptability. When the $\mathrm{pH}$ value was 8.4 , the activities of lipase and (SBA-15)-lipase were significantly reduced. This may be due to that $\mathrm{pH}$ value was too high, making the conformational of lipase change. Compared with free lipase, post-immobilized lipase catalytic activity was increased. Fig. 12 showed the effect of temperature on the catalytic activity of lipase and (SBA15)-lipase. According to the curves, it can be known that lipase catalysis temperature optimum condition was $35^{\circ} \mathrm{C}$ and (SBA15) -lipase catalysis temperature optimum condition was 45 ${ }^{\circ} \mathrm{C}$. The catalytic activity at this time was $87.4 \mathrm{U} / \mathrm{g}$. This showed that the immobilized lipase was still not easy inactivated at a higher temperature, having a definite characteristic of enduring to high temperature. The reason is that lipase was adsorbed inside SBA-15. From the heat transfer theory, it is known that the internal temperature was much lower relative to the SBA15 surface temperature. At the same time, the interaction of lipase and SBA-15 hydrogen bonding also accordingly decreased the effect of temperature on its activity. Post-immobilized lipase catalytic activity was increased compared with free lipase. The immobilized lipase showed more stable properties to both $\mathrm{pH}$ and temperature environment, which can be attributed to the cage itself of SBA-15 and the rigidity of the $\mathrm{SiO}_{2}$ matrix. This reduced the freedom of peptide-chain refolding molecular motions that occur in protein denaturation processes. The reuse activity experimental results of (SBA15)-lipase showed that as the repeated use times of (SBA-15)lipase increased, its catalytic activity was descending. When the repetition times reached four times, the activity of (SBA15)-lipase achieved $18.8 \%$ of the best activity. This is because in the reuse process via reduplicative washing, filtering this made the intermolecular weak force between the lipase and SBA-15 be decreased, leading to the loss of lipase, making the catalytic activity of (SBA-15)-lipase be decreased. The experimental results showed that when the [Ph-(SAB-15)]lipase was reused six times, its activity reached $19.1 \%$ of optimum activity. The repeated use time of post phenylated material [Ph-(SAB-15)]-lipase is higher than that of (SBA15)-lipase,indicating that "leakage" of the enzyme was reduced in the host materials after the phenylation of SBA-15.

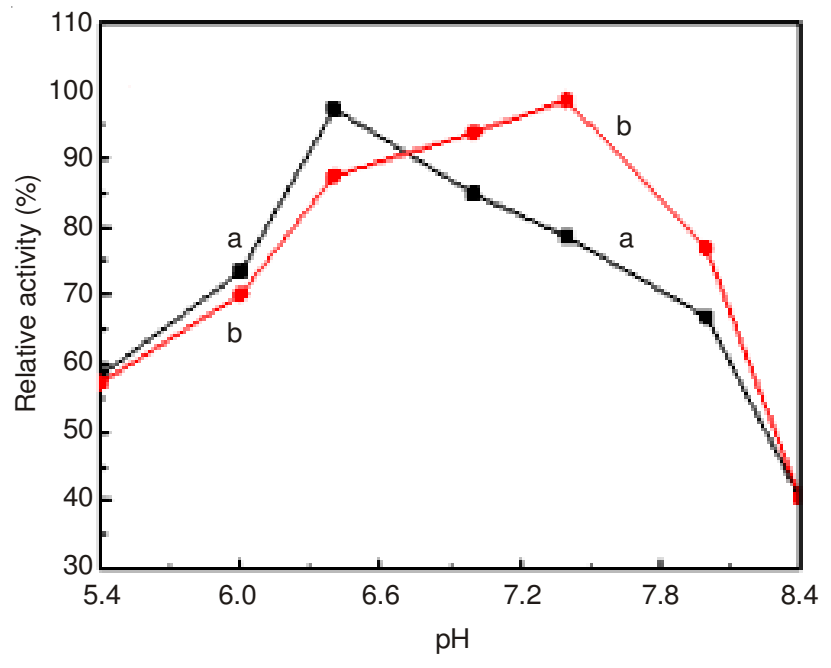

Fig. 11. Effect of $\mathrm{pH}$ value on catalytic activity: (a) lipase, (b) (SBA-15)-lipase

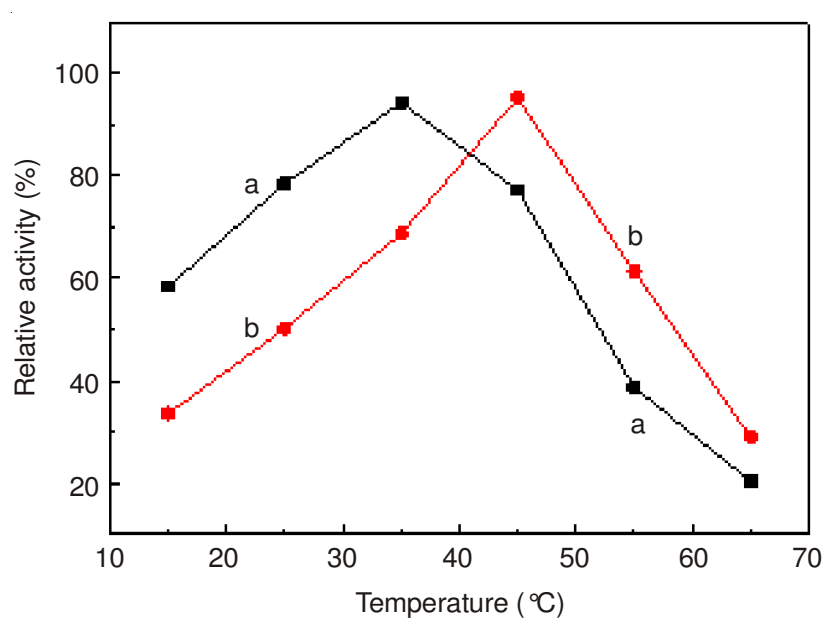

Fig. 12. Effect of temperature on catalytic activity: (a) lipase, (b) (SBA15)-lipase 


\section{Conclusion}

Using physical adsorption method,the immobilization of lipase into SBA-15 and phenylated SBA-15 was successfully achieved, respectively. The adsorption capacity and rate of adsorption is strongly dependent on the $\mathrm{pH}$ value of immobilization solution. The maximum adsorption occurs near the isoelectric point of lipase at $\mathrm{pH}=6.4$, and afterwards an increase in $\mathrm{pH}$ decreases the adsorption capacity due to electrostatic repulsive force increase. SBA-15 can obtain higher specific surface area, and this can result in higher enzyme adsorption capacities. By means of powder XRD, Fourier transform infrared spectroscopy and luminescence spectroscopic characterization, it has been indicated that after lipase was immobilized in SBA-15 and phenylated SBA-15, the frameworks of host materials were of integrity and the SBA-15 structure was not obviously affected by the procedure used for enzyme immobilization and the lipase conformation was not destructed and the protein was not denatured. Scanning electron microscopy experiments showed that the immobilized composite material presented fibrous form. The average particle sizes of (SBA-15)-lipase and (phenylated SBA-15)lipase were $337 \pm 10 \mathrm{~nm}$ and $340 \pm 10 \mathrm{~nm}$, respectively. $77 \mathrm{~K}$ low temperature $\mathrm{N}_{2}$ adsorption-desorption studies suggested that the lipase has been successfully immobilized inside the channels of host materials. Luminescent spectra indicated that the composite materials have the very good luminescence characteristic. The composite materials prepared in the present study have very high catalytic activity and reuse availability, which has an important significance for industrial manufacturing cost reduction.

\section{ACKNOWLEDGEMENTS}

The authors gratefully acknowledge the financial support from the Natural Science Foundation of Jilin Province, P. R. China for this work under Grant No. 201215146, 242920, KYC-JC-XM-2012-059.

\section{REFERENCES}

1. A.I. Kallenberg, F. van Rantwijk and R.A. Sheldon, Adv. Synth. Catal., 347, 905 (2005).

2. B. Zhao, B. Shi and R. Ma, Eng. Life Sci., 5, 436 (2005).

3. J.S. Beck, J.C. Vartuli, W.J. Roth, M.E. Leonowicz, C.T. Kresge, K.D. Schmitt, C.T.W. Chu, D.H. Olson and E.W. Sheppard, J. Am. Chem. Soc., 114, 10834 (1992).

4. C.T. Kresge, M.E. Leonowicz, W.J. Roth, J.C. Vartuli and J.S. Beck, Nature, 359, 710 (1992).

5. D.Y. Zhao, J.L. Feng, Q.S. Huo, N. Melosh, G.H. Fredrickson, B.F. Chmelka and G.D. Stucky, Science, 279, 548 (1998).

6. D.Y. Zhao, Q.S. Huo, J.L. Feng, B.F. Chmelka and G.D. Stucky, J. Am. Chem. Soc., 120, 6024 (1998).

7. M.F. Ottaviani, L. Mollo and B.J. Fubini, J. Colloid Interf. Sci., 191, 154 (1997).

8. B. Menaa, F. Menaa, C.A. Guimaraes and O. Sharts, Int. J. Nanotechnol., 7, 1 (2012).

9. B. Menaa, Y. Miyagawa, M. Takahashi, M. Herrero, V. Rives, F. Menaa and D.K. Eggers, Biopolymers, 91, 895 (2009).

10. J.F. Diaz and K.J. Balkus Jr., J. Mol. Catal. B, 2, 115 (1996).

11. H.H.P. Yiu, P.A. Wright and N.P. Botting, Micropor. Mesopor. Mater., 44-45, 763 (2001).

12. L. Ji, A. Katiyar, N.G. Pinto, M. Jaroniec and P.G. Smirniotis, Micropor. Mesopor. Mater., 75, 221 (2004).

13. B. Stellmach, Determination Method of Enzyme, China Light Industry Press, Beijing, p. 211 (1992).

14. Z. Luan, M. Hartmann, D. Zhao, W. Zhou and L. Kevan, Chem. Mater., 11, 1621 (1999).

15. Q.Z. Zhai and D. Yang, Asian J. Chem., 21, 2207 (2009).

16. Q.S. Wang, Q.Z. Zhai and J. Luo, Asian J. Chem., 25, 5470 (2013).

17. S. Brunauer, P.H. Emmett and E. Teller, J. Am. Chem. Soc., 60, 309 (1938).

18. E.P. Barrett, L.G. Joyner and P.P. Halenda, J. Am. Chem. Soc., 73, 373 (1951).

19. G.A. Parks, Chem. Rev., 65, 177 (1965).

20. S.W. Song, K. Hidajat and S.F. Kawi, Langmuir, 21, 9568 (2005).

21. T.P.B. Nguyen, J.W. Lee, W.G. Shim and H. Moon, Micropor. Mesopor. Mater., 110, 560 (2008).

22. Y.G. Liu, Q. Xu, X.M. Feng, J.J. Zhu and H.W. Hou, Anal. Bioanal. Chem., 387, 1553 (2007).

23. K.S.W. Sing, Pure Appl. Chem., 57, 603 (1985). 